\title{
Malignant Ovarian Mucinous Tumor
}

National Cancer Institute

\section{Source}

National Cancer Institute. Malignant Ovarian Mucinous Tumor. NCI Thesaurus. Code C40033.

An invasive malignant neoplasm that arises from the ovary and is characterized by the presence of malignant epithelial cells that contain intracytoplasmic mucin and may resemble the epithelial cells of the endocervix or gastrointestinal tract. It includes mucinous adenocarcinoma and mucinous adenocarcinofibroma. 